\title{
Sexism in English Proverbs and Idioms
}

\author{
Ali He \\ Shanxi Normal University, Shanxi, China \\ Yang Zhang \\ Shanxi Normal University, Shanxi, China
}

\begin{abstract}
The study of "language and gender" has been always popular among linguistics. Language, as a mirror of the society, reflects a nation's values and beliefs. Sexism against women has been common in English-speaking countries. So we can also see sexism in English here and there. Proverbs and idioms are blood and guts of a nation. This paper pays much attention to the sexism in English proverbs and idioms. This paper first discusses the preview studies about sexism and the definition of English proverbs and idioms; and then the thesis expounds the manifestations of sexism in proverbs and idioms from the perspectives of social status, wisdom, character, and marriage; then the paper also makes deep studies into the causes of sexism from three aspects: society, culture and psychology; finally, this paper indicates the development trend of sexism in English proverbs and idioms. Through the studies on English proverbs and idioms, this paper tries to reveal the phenomenon of sexism in language and find out solutions to help people reduce and eliminate discrimination against women in society and language.
\end{abstract}

Index Terms — sexism, English Proverbs and idioms, manifestation, causes, development trend

\section{INTRODUCTION}

According to Edward Sapir (2014), we can see that language is a guide to social reality. Language, as a mirror of the society, can not only reflect a nation's culture and history, but also reflect its values and beliefs. Language and gender are popular fields in sociolinguistics. As we know, sexism is a common phenomenon of the society. And in the process of the studies on this issue, language has played an important role.

The phenomenon of discrimination against women exists in English-speaking countries, so we can see sexism in English here and there. English proverbs and idioms are often taken as the blood and guts of English, they are important parts of English and popular among people. So studying sexism in English proverbs and idioms helps us understand sexism in English-speaking communities.

So in this paper, the author tries to analyze sexism in English proverbs and idioms and find out its origin. However, the studies on this issue made by researchers are not rich and profound. So, this paper tries to study sexism on this aspect and understand the values and beliefs of life of people from English-speaking communities. We can also grasp historical pulse of the development of English. Doing researches on this issue helps us make English communications successfully.

\section{LiteratURe REVIEW OF SEXISM, PROVERB AND IDIOM}

\section{A. Literature Review of Sexism}

1. Definition of Sexism

Sexism refers to the prejudice or discrimination involving in sex. It often refers to the discrimination against women. The inequality of two sexes causes sexism in society. And sexism can also be defined as the unfair and unreasonable discrimination between sexes. Therefore, sexism is a kind of system of beliefs and rules that confirm the dominance of men over women. Anne Pauwels(1998) examines how sexism works in language in her book A Women Changing Language. Sexism in language refers to the phenomenon that we use some language containing discrimination against women. Sexist language refers to the expressions that differentiate between men and women or eliminate, trivialize either gender.2. Studies on Sexism

Sexism especially refers to the phenomenon of discrimination against women. It is common in society and reflected in language, that is linguistic sexism. Linguistic sexism is the language that assures one sex dominates the other one, that is, the language that favors the male, and degrades the female.

Sexism is a common phenomenon since our human history. Jennifer (1993) once said sexist language not only reflects the stereotyped attitudes to men and women, but also reflects the values and beliefs of a nation. The discrimination against women is inherited from one group to another and from one generation to the next. With the development of movement of feminists for woman's rights, the phenomenon of sexism against women is gradually eliminated. And women will be treated equally in the future.

\section{B. Literature Review of English Proverb and Idiom}




\section{Definition of Proverb}

The proverb is a unique form of language. It is popular among people. English proverb contains the common sense and the practical experience of humanity. It is a kind of folk literature. Proverb, as one of the varieties of language, is human being's crystallization of wisdom. It embodies the concise language. English writer William Penn once said: "The wisdom of nation lies in their proverbs." And some people thought that proverbs were embodiment of daily experience. The proverbs are produced on the basis of cultural concepts and social encyclopedia. Proverb is useful in people's daily life. It helps people recognize life, find the meaning of life and even encourage people's will. It plays an important role in people's life. As a product of culture, the proverbs, the special form of language, are used to reflect a nation's social life, custom and mode of thinking.

According to Longman Modern English Dictionary (2004), proverb is a brief maxim of folk literature. And it is often compressed in form, usually describing certain image. So we can find the features of proverbs as followed.

(1) Created and used in non-standard situations

As we know, proverb is a kind of folk literature. Folk literature is the literature that is created by ordinary people in their daily life. It is often circulated by oral form and continuously changed with the development of the society. Most of the English proverbs are created by ordinary people in their labor. They are not created by the officials and scholars. Lots of workers, such as peasants, hunters, sailors and cookers get experience from their work and labor. Then, they use a relatively easy and informal way instead of a complex and stand one to systemize these experiences and introduce them to their descendants, that is proverb, With the development of history, the proverbs are gradually circulated in people's communication, often in family communication and other relatively informal contexts.

(2) Expressing a truth, encouraging people's will and thought and educating people some lessons.

The proverbs are the form of the experience gotten by ancestors in their former life. The contents of proverbs are abundant. And the meanings are profound, full of philosophy. We can get inspiration from them for thought. English proverbs mostly contain abundant meaning and contents. People often use them as a guide to action. In lots of situations, English proverbs can become the good teacher and best friends of people. People who read proverbs will get inspiration for thought and receive plentiful experience and lessons. Maybe we can find the shade of proverbs in one's growth.

(3) Simple and straightforward, easy to understand.

As we know, the proverbs are created by laboring people. The most English proverbs are relatively concise and easy to understand and grasp. Only a few words of them will contain much complex form and plentiful contents, which are used to express deep lessons and provide source for thoughts. The proverbs are passed on by oral form, so they are often relatively easy to remember.

(4) Harmonious rhyme, easy to read.

In order to encourage the spread of proverbs, the creators of English proverbs will pay much attention on the rhyme of proverbs. They created harmonious rhyme to help the widely spread of English proverbs. They often use alliteration, parallelism or others to produce the impact of beautiful phonetic rhyme.

2. Definition of Idiom

Idiom is an important part of English. It is the concise phrase or short sentence which is used by ordinary people in daily life. In this paper, we refer the idiom to the concise phrase. Idiom consists of more than more words. The meaning of the whole idiom has some differences with the separate words. So it is difficult to find the real meaning from the literal meaning. English idiom is a special form of language. It is the mirror of the culture of the western countries. People put a high value on idioms. English idiom is often taken as the blood and guts by the English-speaking people. It is widely used in spoken and written communications.

English idiom has unique word construction. It can make the ordinary word produce magic effect. The meaning and structure of English idioms are special and elegant.

(1) A unity of meaning

English idiom consists of more than one word. Every word loses its own original meaning. And they combine with each other to form an entry to express certain meaning. So we can't find the real meaning of the whole English idiom, if we only discriminate the class and meaning of every isolate word. For example, in the following phrase: cap in hand, cap is a noun, in is a preposition, hand is also a noun. However, the meaning of the whole phrase is not that one has a cap in hand, it's real meaning is that someone do something in a very polite way. So the whole phrase is used as an adverb.

\section{(2) Fixed structure}

The construction of English idiom is relatively fixed. The words which are used to construct English idioms can't be exchanged by other words. And the order of the words can't be changed. For example, the following idiom: at sixes and sevens can't be exchanged by at sevens and sixes. In addition, there are many idioms which are non-conformity with the phrase rule, but the structure of them can't be changed randomly. There are some other examples: Diamond cut diamond, Money makes the more to go, Rain cats and dogs.

\section{MANifESTations OF SEXISM In ENGlish ProverbS AND IDIOMS}

A. Manifestations of Sexism in English Proverbs

1. The Accessory Position of Women 
When human history developed into the patrilineal society, men began to become the center of the society. In the history of western or eastern countries, women were in the low position and discriminated by the society. Christianity prevails in the western countries and the accessory position of women was also reflected in Bible. According to Bible, God made men firstly and let them become the dominance of the whole world. However, woman is just one rib of man. So we can see that Bible plays the men into the dominate position and women into the accessory position. In English proverbs, there are some examples containing this thought:

(1) A man of straw is worth of a woman of gold.

(2) If the husband be not at home, there is nobody.

(3) Man, woman and devil are three degrees of comparison.

The above proverbs all contain sexism. We can find male chauvinism in them. And they reflect the fact that women are oppressed and insulted by the society. In the second example, it says that if the husband is not here, there is nobody. It expounds an obvious fact that woman is always ignored and the husband, that is man, is always regarded as the center of the family and society. Women always do the most tired and bored housework, but they still can not be respected by husbands and the society. And in many situations, women are in the secondary position. They do not have the equal place with men and are always in the accessory position.

2. The Inferiority of Woman's Character and Wisdom

In western history, women had little chances to receive the normal education. And often the higher education was only for men. In tradition, there was a common practice that ignorance is woman's virtue. So women were not advocated to receive education. Because of the fact that women were deprived of the chance of education, women were not as sophisticated as men. And in most situations, the famous scientists and great people were always men. So because of the traditional practice and the common phenomena, the contribution of women was always ignored by others. However, the ignorance of women was belittled by the society. In addition, in the western culture, women were always connected with some bad aspects, they were often the synonym of vanity, weakness and tears. English has many proverbs that satire these shortcomings of women about character, for example:

(1) A woman's advice is never to seek.

(2) A woman and a glass are ever in danger.

(3) Women are wavering as the wind.

The above proverbs all reflect sexism against women about character and wisdom. In western history, the contribution of women always was ignored. In the first example, the opinions of women are not cared. Their thoughts are regarded as trash and have no reference value. This reflects that woman's wisdom is degraded and nobody cares about how they think. In the second example, woman's character is fragile and has the same feature with glass. Although they have done great contribution in some historical movements, in most situations, they are always the synonym of vanity, weakness and tears.

3. The Lower Position of Women in Marriage

Marriage is an important aspect of culture. It reflects the social and cultural view of one community. There are two kinds of proverbs in English about marriage. One reflects the urgent wish to marry daughters. The other one is concentrated on the chastity of women. Both of these two kinds reflect the discrimination against women. Women always bear a lot in marriage. They need to do lots of housework and other things, but they still can not be respected by husbands and the society. We can see this phenomenon in the following proverbs:

(1) Daughters and dead fish are not keeping wares.

(2) It is harder to marry a daughter well than to bring her up well.

(3) Marry a wife of thine own degree.

These proverbs emphasize the center of men in marriage and make women become the commodity and doll. In the first proverb, it reflects the urgent wish to marry daughters but not sons. In a family, the wives and daughters are always not regarded the real part of the entirety. In the western history, when there were some important fairs in family, the wives could not ask in detail and give her own ideas. They were in the lower position in marriage. In the third example, when a man want to marry someone, he would consider the wife's family status and always wants to marry a woman who can deserve him but not consider his own conditions at first.

\section{B. Manifestations of Sexism in English Idioms}

\section{The Inferiority of Woman's Character and Wisdom}

With the development of society and history, in many situations, when we refer to women, we will think of the character of gregarious, frail, emotional, irrational and so on. These words obviously reflect sexism against women about character. There is nobody who settles these characters on women, but we often contact them with women. And they are inevitably reflected in the daily communication. They are not only reflected in proverbs but also reflected in idioms. There are many English idioms reflect this phenomenon. For example:

(1) Nice Nelly

(2) Alley Cat

(3) Aunt Sally

In the above idioms, we can obviously see the fact that woman's characters are degraded. In the first idiom, when people want to describe the bad personality, they will use the words connected with woman. "Nelly" has the meaning of 
feminization. And people use it to express the evil aspect of characters. In the third idiom, when people refer to the opposite thing, they also use feminine words.

1. The Lower Position of Women in Marriage

Family is the basic unit of society which is established on the basis of marriage. So it is necessary to pay attention to the idioms about family. According to many studies, the idioms about family reflect the low position of women. Women often depend on men in economy and they are engaged with housework. But they can't receive respect from men. We can take the idiom of Golf Widow as an example. In this example, people put man in the major place, and women are regarded as the accessory of man. In people's idea, women depend on man, and they can not live a good life without men.

2. The Passivity of Sex for Women

In English, there are many idioms of women having contact with sex. And women are always in the passive position. People often connect the bad things with woman in sex. There are some examples: A woman with a past Call girl, Make an honest woman of somebody. From the above idioms, we can see that the idioms of women about sex reveal the phenomenon of discrimination against women. Women are paid much attention on the aspect of sex, not as a human. In addition, women are always belittled because of sex permissiveness. They are taken as sex tools by men. However, if the men be open in sex, they will be tolerated.

\section{Causes of SeXism in the English Proverbs And Idioms}

Sexism in English proverbs and idioms is the real reflection of social sexism. It is not the language that contains sexism. It is the result of society, history and culture. The reasons of this phenomenon contain many aspects. They are social factors, cultural origin, and psychological reasons and so on.

\section{A. Social Factors}

From the patrilineal society, men were the center of the whole world, when human history entered into patriarchy society, the discrimination against women was institutionalized. And the view that men were superior to women becomes the custom of the society. Men gradually become more and more dominant in the society. And women were in the low and accessory position. However, in modern society, people also accept this practice. They believe that in a typical family, the man should mainly deal with social affairs and the woman should mainly deal with domestic affairs. Because of the different social division of labor and social status, men gradually occupied the dominant position in society and women were in the subordinate position. Language is the mirror of the society. So this phenomenon of discrimination against women can be reflected in the language. The dominant position of male language reflects the main position of men in the society, and the accessory position of female language is the reflection of subordinate position of women.

\section{B. Cultural Origin}

Language is a mirror of the society. It reflects a nation's values and culture. So the phenomenon of sexism has deep cultural origin. A lot of English proverbs and idioms originated from many myth and literary writings. And in many cases, these myth and writings contain much sexism.

(1) Sexism in myth

Religion has played an important role in the development of western cultural history. Bible is always taken as the key to western culture. Linguistics often pay much attention on it. So, in the studies of reasons of sexism, we can't ignore the influence of Bible. According to Bible, God made Adam firstly and then created Eve using Adam's rib. When God took Eve to meet Adam, Adam said: "this is now bone of my bones, and flesh of my flesh; she shall be called woman, because she was taken out of man." We can see sexism in this sentence. And in many Greek myths, we also can find discrimination against women. This view originating from western myth gradually became a kind of practice, penetrated into every aspects of society, and provided seeds for sexism.

(2) Sexism in writings

There were many outputs containing much sexism. Among them, the works written by Shakespeare are outstanding examples. In Shakespeare's famous tragedy Hamlet, he once said: "Frailty, thy name is woman." In this play, we can see that the queen put her destiny and happiness on marrying a good man, which contains a lot of blood and tears of women in the class society.

\section{Psychological Reasons}

Men and women have different characters. They are different on aspects of perception, thought, emotion, and ability. The differences on these aspects play an essential role on the formation of sexism. In addition, the practice that men should have masculinity, that is, men should be in the dominant position, be brave and not be feminine, and women are in the opposite side, should not be ignored on the process of formation of sexism. In tradition, women should have femininity, which means that women should be tender, considerate, shy and sentimental. On the influence of this tradition, women always pay much attention on the elegance and standardization of their language when they communicate with others. They hope to be accepted by other people, so they always use pleasant words and sentences. 
However, in psychology, on the influence of this practice, woman will tend to make herself as a contemptuous figure, which strengthens the discrimination against them.

\section{Development TREND OF SEXISM In The ENGLiSh ProverbS AND IDIOMS}

Due to historical factors, cultural origin and psychological reasons, the views of sexism root deeply in people's mind and they are gradually reflected on every aspect of life. However delightfully, with development of movement for woman's rights, the feminists have tried their best to eliminate sexism in English. And they got lots of amazing achievements; we can see them in the following aspects:

(1) In language, there are gradually more and more neutral words which are used to replace the masculine words. For example, businessperson is used to replace businessman, salesperson is used to replace salesman, and police officer is used to replace policeman.

(2) There are some changes in address. In some countries, women have the rights to use their own family name but not their husband's. And Ms is used to replace Mrs and Miss.

(3) There also appears many feminine words or changes the masculine words into the plural of neutral words. For example, in the following sentence, someone left his or her book on the desk.

(4) There are some amendments in legislation. The western country governments have eliminated sexism in legislation; they made some laws and rules to assure the equality between men and women.

Although the feminists have made great contribution in changing sexism, this way is very long and rough. As we know, language is the mirror of the society. It is not the language that is sexist, it is the society. So if we want to eliminate sexism in language, we should change the social opinion of sexism firstly. The reform of language should be established on the basis of social reform.

\section{CONCLUSION}

Language is the mirror of the society. Sexism in language reflects sexism in society. And proverbs and idioms are important parts of English. Through studying sexism in English proverbs and idioms, we can better understand the phenomenon of sexism in society. To some extent, for lots of English learners, learning the English proverbs and idioms equals rearing the soul of English. When we communicate with foreigners, we should try to avoid using proverbs and idioms with sexism.

It is not the language that is sexist, it is the society. So in order to clear away the phenomenon of sexism in English proverbs and idioms, we should change the society firstly. We must try to change people's deep-rooted wrong thoughts, reform the legislation and eliminate the phenomenon of sexism in society. Then the sexism in English proverbs and idioms will die out and some new words which respect and admire women will be created.

We hope that the ideas of equality between men and women can be rooted deeply into people's heart, and women can be treated equally in the future.

\section{ACKNOWLEDGEMENTS}

Owing to my partner's wisdom, enthusiasm, support and encouragement, I can finish this paper smoothly. It is her profound knowledge and insights that help me overcome many difficulties and master basic writing skills. Without her revising for several times, this paper would not be what it is now.

My sincere thanks are also due to my colleagues. They have taught me a lot of knowledge about how to write a successful paper. But for their patient explanation, I can't grasp the tips of writing thesis.

Finally, I give my heartfelt thanks to my dear friends. They help me a lot in the process of finishing this paper. They have not only offered me their warm encouragement but also shared me with their ideas and books. Our friendship is always a treasure and a driving force to me.

\section{REFERENCES}

[1] Coates, Jennifer. (1993). Women, men and language. London: Longman.

[2] Edward, Sapir \& Sam, Sloan. (2014). Language. Japan: Ishi Press.

[3] Longman Dictionary of Contemporary English. (2004). Beijing: Foreign Language Teaching and Research Press.

[4] Pauwels. (1998). A Women Changing Language. London: Longman.

[5] Yang XinYing. (2008). Gender Discrimination in English Proverbs and Idioms. Shanghai: Profile of Shanghai Jiao Tong University Press.

Ali He was born in Shanxi, China in 1972. She is associate professor at Shanxi Normal University. Her highest degree is a doctor's degree.

She is currently a teacher in Shanxi Normal University, Shanxi, China. Her research interests include Applied Linguistics, Cognitive Linguistics and Comparison between English and Chinese. 
Yang Zhang was born in Shanxi, China in 1993. She received her Bachelor's degree in English from Lvliang University, Shanxi, China in 2015.

She is currently studying for Master's degree in Shanxi Normal University, Shanxi, China. Her research interests include Cognitive Linguistics and Social Linguistics. 